\title{
Reducing preventable patient transfers from long-term care facilities to emergency departments: a scoping review - CORRIGENDUM
}

\author{
Kiran L. Grant, Daniel Dongjoo Lee, Ivy Cheng, G. Ross Baker
}

doi: $10.1017 /$ cem.2020.416

In the original publication of Grant et al. 2020, co-author Daniel Dongjoo Lee's name was presented incorrectly.

The original has been updated to correct this error.

\section{Reference}

Grant KL, Lee DD, Cheng I, Baker GR. Reducing preventable patient transfers from long-term care facilities to emergency departments: a scoping review. CFEM. Published online 3 August 2020. doi:10.1017/cem.2020.416 